\title{
RECOVERY BY MEANS OF ELECTRODIALYSIS OF AN AROMATIC AMINO ACID FROM A SOLUTION WITH A HIGH CONCENTRATION OF SULPHATES AND PHOSPHATES
}

\author{
V. Montiel,V. García-García. J. González-García, F. Carmona y A. Aldaz. \\ Departamento de Química-Física. Universidad de Alicante. Apdo. 99. E-03080. \\ Alicante. Spain.
}

\begin{abstract}
Summary.
In the industrial obtention of D- $\alpha$-p-hydroxyphenylglycine the separation of the amino acid is carried out by precipitation and during this process, a mother liquor is produced with a high salt content (phosphates and sulphates) and an amino acid concentration of approximately $120-150 \mathrm{~mol} \cdot \mathrm{m}^{-3}$. The disposal of this mother liquor not only suppose an environmental problem for its high salinity and COD (Chemical Oxygen Demand) content but also an economic lost due to the high price of the unrecoved amino acid. To avoid this problem an electrodialytic process has been developped that allow the recovery of $85 \%$ of the amino acid in the form of a low salinity stream with a salt content a $70 \%$ lower than that the initial mother liquor. This low salinity stream can be incorporated to the main process and in this way the amino acid can be recover.
\end{abstract}

Key words: D- $\alpha$-p-hydroxyphenylglycine, desalting, electrodialysis.

\section{Introduction.}

Desalting of aqueous solutions containing organic products can be carried out by several procedures. The classic one is based on the decrease of the dielectric constant of the solvent by addition of an organic solvent miscible with water, i.e. methanol. This decrease produces the precipitation of the salt that is removed by filtration and centrifugation. The organic solvent is recovered by destillation while the organic product remains in the aqueous solution. The principal drawbacks of this procedure is that the number of the unit operations is increased and this increases the complexity of the process and the cost of the product. Moreover, the toxicity and dangerous handling of the organic solvent require the use of strong safety measurements.

Other possibility is to use a membrane process, particularly Electrodialysis. This technique is a well known, useful and elegant membrane process for the desalting of solution containing organic products.. The desalting increases not only the yield of the precipitation process by decreasing the saline effect but also the quality of the final product. In an Electrodialysis stack, desalting of the solution is carried out by means of an electric field. This field is created by the application of a potential difference between two terminal electrodes of a stack in which several compartments formed by cationic and anionic membranes alternatively arranged exists. In order to transport the current, ions migrate through the membranes; cations to the cathode through the cationic membranes and anions to the anode through the anionic ones. In this way the organic 
containing solution, normally called diluate, is desalted, being the salt transported to the compartment containing the so called concentrate.

This membrane process is particularly useful for the desalting of solutions containing amino acids. Thus, during the last years, a great number of publications and patents on electrodialytic desalting have appeared, (1-8)in which the typical cationic and anionic exchange membranes are used. Recently, Sato et al (9) have proposed an alternative to conventional electrodialysis by using a charge mosaic membrane to remove salt with a minimal amino acid loss. The authors claim that this loss is lower than that obtained using the conventional electrodialysis membranes. However it must pointed out that the solutions they treated contains amino acids in a relatively low concentration, $10 \mathrm{~mol} . \mathrm{m}^{-3}$.

D- $\alpha$-p-hydroxyphenylglycine plays an important role as constituents of pharmaceuticals. Well known examples are $\beta$-lactam antibiotics such as Ampicillim, Amoxicilim, Cephalexim and Cefadroxil where the unnatural side-chains are :D-phenylglycine and $\mathrm{D}$-p-hydroxyphenylglycine. One of the process for the production of the D- $\alpha$-amino acids is the stereospecific splitting of 5-substituted hydantoins to the corresponding D$\mathrm{N}$-Carbamoylates. The remaining L-5-hydantoin is racemized leading to the total conversion to the enantiomerically pure D-N-Carbamoylate, and this one is splitting into D-amino acid by chemical or enzymatic means.

The separation of the amino acid is carried out by precipitation by working- up the $\mathrm{pH}$ of the solution to the isoelectrical point of D- $\alpha$-p-hydroxyphenylglycine. Then, amino acid is removed by centrifugation. The residual water(mother liquor) contains amino acid in a concentration between 110-120 mol m $\mathrm{m}^{-3}$ and ammonium and sodium sulphate and phosphate in high concentration.

The aim of this work is to develop an electrodialytic process for desalting this residual water containing D- $\alpha$-p-hydroxyphenylglycine (120-150 mol. $\mathrm{m}^{-3}$ )and ammonium and sodium sulphates and phosphates in high concentration $\left(2000 \mathrm{~mol} . \mathrm{m}^{-3}\right)$. The loss of amino acid must be small in order to recover a sustantial amount of this expensive chemical. The diluate obtained could be send to the precipitation step after a concentration step if needed, increasing in this way the yield of the production of amino acid. Fig. 1 shows a scheme of the process. 


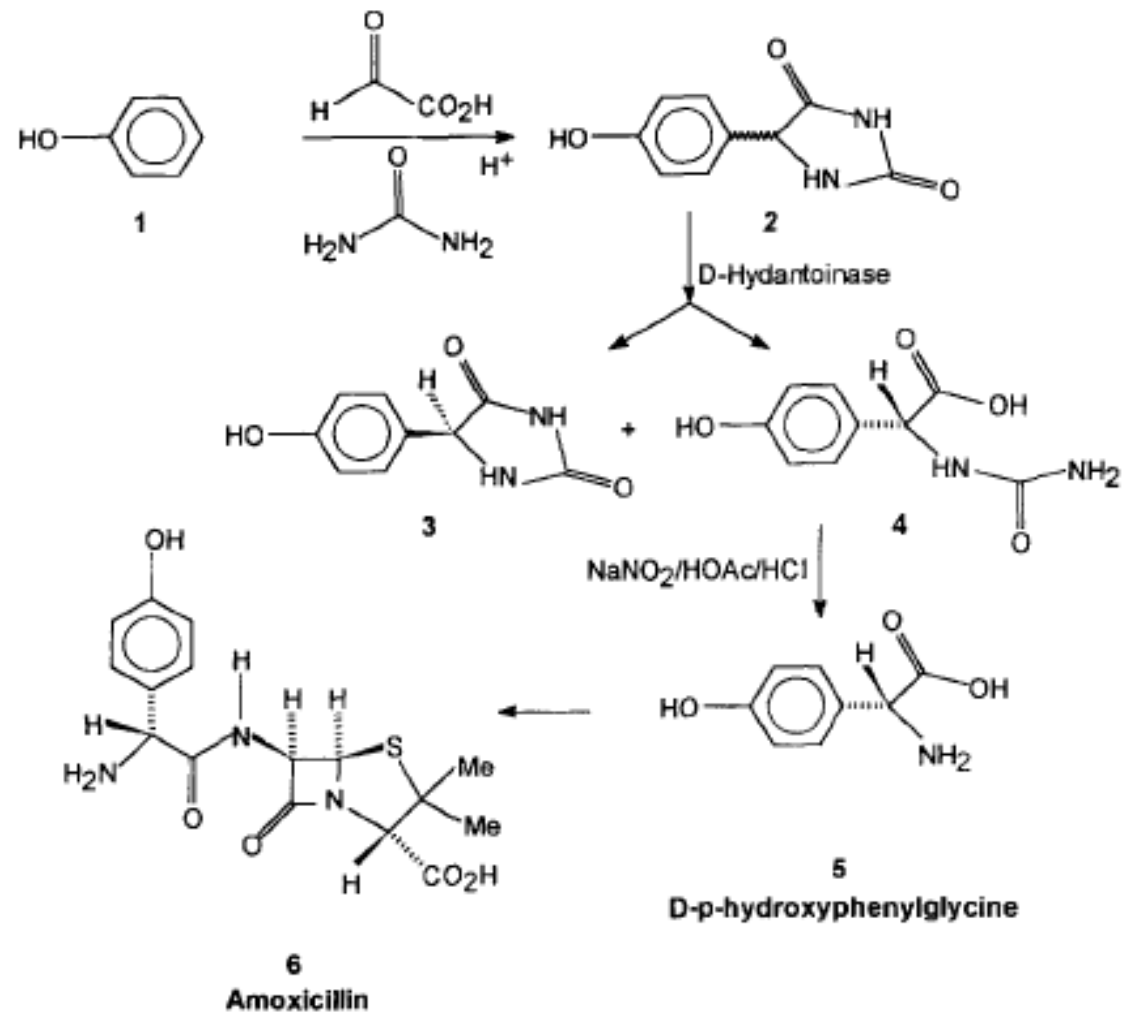

Fig. 1. Scheme of the overall process of synthesis of amoxicillin from phenol.

\section{Experimental.}

The experiences were carried out using an EURODIA TS2-10P electrodialysis stack with a total membrane area of $2000 \mathrm{~cm}^{2}$ (10 cell pairs per stack). The electrodic materials were SYS.316 stainless steel for the cathode and platinized titanium for the anode. Both electrodes have an effective area of $200 \mathrm{~cm}^{2}$. A CMX cation and an AMX anion exchange membranes from Tokuyama were employed. Fig.2 shows a scheme of an electrodyalyzer with two cell pairs. The feed solution for cathodic and anodic chambers was a $500 \mathrm{~mol} . \mathrm{m}^{-3} \mathrm{NaH}_{2} \mathrm{PO}_{4}+500 \mathrm{~mol} . \mathrm{m}^{-3}\left(\mathrm{NH}_{4}\right)_{2} \mathrm{SO}_{4}$ solution. The concentrate was initially $45 \mathrm{~mol} . \mathrm{m}^{-3} \mathrm{NaH}_{2} \mathrm{PO}_{4}+45 \mathrm{~mol} . \mathrm{m}^{-3}\left(\mathrm{NH}_{4}\right)_{2} \mathrm{SO}_{4}$ solution . The typical composition of the mother liquor (diluate) coming from the industrial process was taken as $111 \mathrm{~mol} . \mathrm{m}^{-3}$ of amino acid +687 mol. $\mathrm{m}^{-3} \mathrm{NaH}_{2} \mathrm{PO}_{4}+1333 \mathrm{~mol} . \mathrm{m}^{-3}$ $\left(\mathrm{NH}_{4}\right)_{2} \mathrm{SO}_{4}$ solution with a pH of 3.8 and an electrolytic conductivity of $12.4 \mathrm{ohm}^{-1} \cdot \mathrm{m}^{-1}$

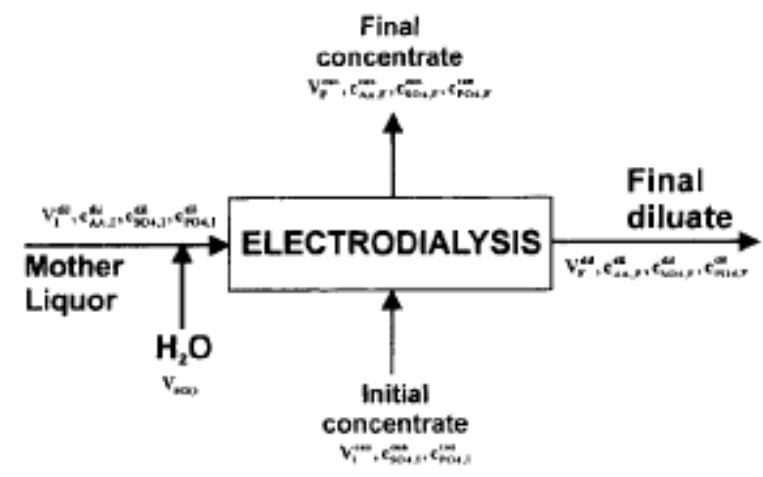

Fig. 2. Mass balance for desalting the mother liquor by electrodialysis. 
The concentration of D- $\alpha$-p-hydroxyphenylglycine was measured by HPLC (Hewlett Pcackard Series 1050) using a RP-18 column and a 25 mol.m ${ }^{-3}\left(\mathrm{NH}_{4}\right)_{3} \mathrm{PO}_{4}$ aqueous solution , $\mathrm{pH}=2.5$, and $\mathrm{MeOH}(90 / 10 \mathrm{v} / \mathrm{v})$ as solvent system. The flow rate was 5.0x10${ }^{7} \mathrm{~m}^{3} \cdot \mathrm{min}^{-1}$. The detector used was a UV detector at $215 \mathrm{~nm}$.

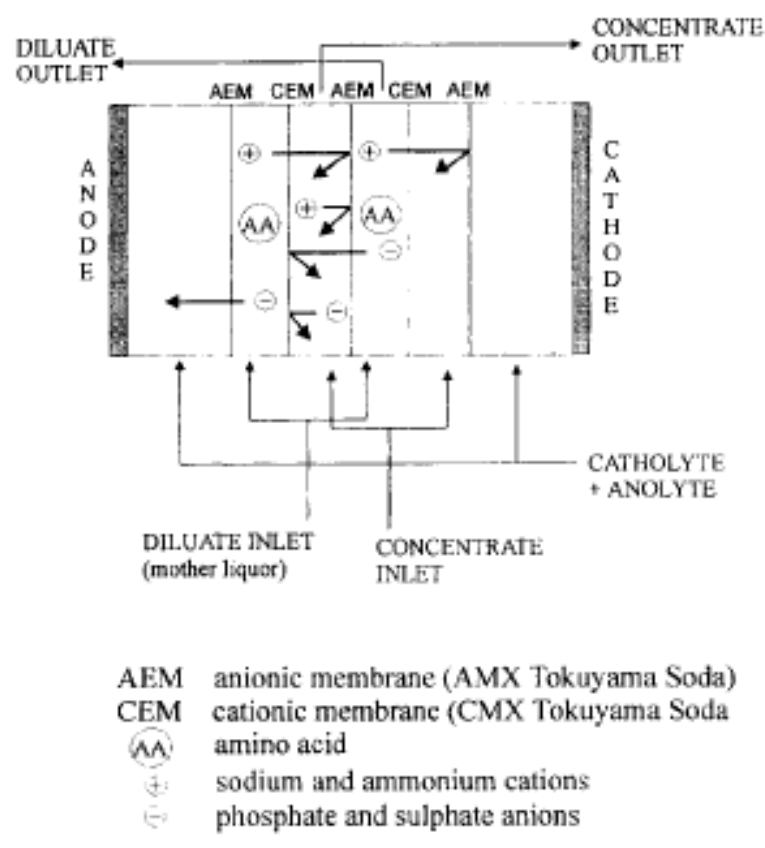

Fig. 3. Scheme of an electrodialyzer with two cell pairs.

The concentration of sulphate and phosphate were determined by Ionic Chromatography using a Metrhom 690 Ion Chromatograph with an ION-120 column. The solvent system was a 4 mol. $\mathrm{m}^{-3}$ sodium salicylate aqueous solution of $\mathrm{pH} 7.8$. The flow rate was $1.0 \times 10^{-6} \mathrm{~m}^{3} \cdot \mathrm{min}^{-1}$.

The loss of amino acid (\%LAA) in the diluate stream is calculated in the following way:

where:

$$
\% L A A=100 \bullet\left[1-\frac{g A A(F D)}{g A A(I D)}\right]
$$

\%LAA : Percentage of loss of the amino acid. gAA (FD) : Grams of amino acid in final diluate gAA (ID) : Grams of amino acid in initial diluate

The removal of sulphate from the diluate was calculate by the following expression:

$$
\% R S O_{4}=100 \bullet\left[1-\frac{g S O_{4}(F D)}{g S O_{4}(I D)}\right]
$$

where:

$$
\begin{aligned}
& \% \mathrm{RSO}_{4}: \text { Percentage of removal of sulphate } \\
& \mathrm{gSO}_{4} \text { (FD) : Grams of sulphate in final diluate } \\
& \mathrm{gSO}_{4} \text { (ID) . Grams of sulphate in initial diluate }
\end{aligned}
$$

The removal of phosphate from the diluate was calculated as following: 


$$
\% R O_{4}=100 \bullet\left[1-\frac{g P O_{4}(F D)}{g P O_{4}(I D)}\right]
$$

where:

$\% \mathrm{RPO}_{4}$ : Percentage of removal of phosphate $\mathrm{gPO}_{4}(\mathrm{FD})$ : grams of phosphate in final diluate $\mathrm{gPO}_{4}$ (ID) : grams of phosphate in initial diluate

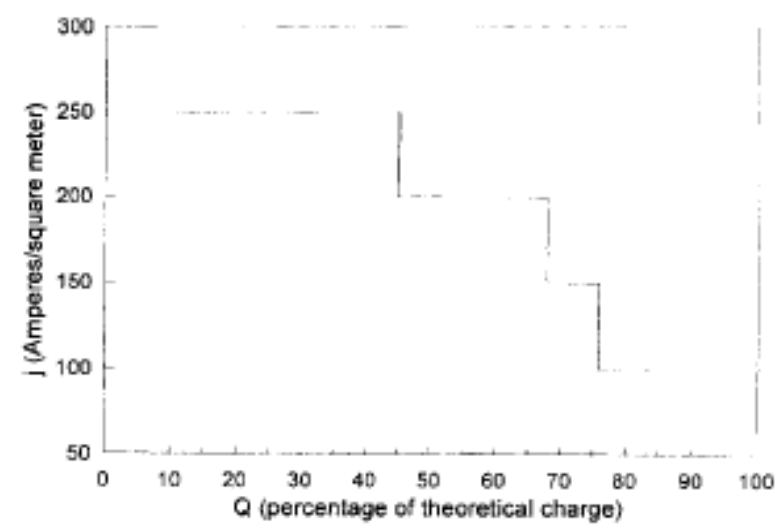

Fig. 4. Current density programme applied without polarisation for different percentages of charge circulated.

\section{Results and Discussion.}

\subsection{Current density program and first studies.}

In order to know the maximum current density that can be used without polarization of the membranes the relation between the potential applied to the electrodialysis stack and the current density was obtained for different amounts of charge circulated. The initial composition of the diluate stream, the concentrate stream and the electrolyte in the cathodic and anodic chambers were given above. Table 1 shows the maximum current density (limiting current density) that can be applied without membrane polarization for the different percentages of charge circulated (Q). This percentage was measured relative to the theoretical charge, i.e, the charge required to remove all the salt from the diluate supposing an ideal behaviour of the selective membranes and that the $\mathrm{H}^{+}$ concentration is so low that his transport number is zero. During the experiences the $\mathrm{pH}$ of the diluate was maintained constant by addition of the required amount of $\mathrm{NaOH}$ (total amount added $32.10^{-3}$ moles).

\begin{tabular}{|c|c|c|c|c|c|c|c|c|c|c|c|c|}
\hline \multirow[t]{2}{*}{$Q(\%)$} & \multicolumn{8}{|c|}{ Diluate } & \multicolumn{4}{|c|}{ Concentrate } \\
\hline & $\mathrm{pH}$ & $\left(\Omega, \mathrm{m}^{-1}\right)$ & $\begin{array}{l}c_{\mathrm{sin}_{4}} \\
(\mathrm{~mol} / /)\end{array}$ & $\begin{array}{l}c_{\mathrm{PO}_{4}} \\
(\mathrm{~mol} / /)\end{array}$ & $\begin{array}{l}c_{\mathrm{AA}} \\
(\mathrm{mol} / \mathrm{l})\end{array}$ & $\begin{array}{l}L_{A A} \\
(\&)\end{array}$ & $\begin{array}{l}R_{\mathrm{SO}} \\
(\%)\end{array}$ & $\begin{array}{l}R_{\mathrm{PO}} \\
(\mathrm{E})\end{array}$ & $\mathrm{pH}$ & $\begin{array}{l}\mathrm{SOO}_{4} \\
(\mathrm{~mol} / \mathrm{t})\end{array}$ & $\begin{array}{l}c_{\mathrm{PO}} \\
(\mathrm{mol} / \mathrm{l})\end{array}$ & $\begin{array}{l}c_{\mathcal{A A}} \\
(\mathrm{mol} / /)\end{array}$ \\
\hline 0 & 3.8 & 12.4 & 1.333 & 0.687 & 0.111 & 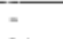 & - & - & 4.5 & 0.045 & 0.045 & - \\
\hline 84 & 3.8 & 7.7 & 0.525 & 0.369 & 0.150 & 24 & 78 & 70 & 4.4 & 1.112 & 0.554 & 0.030 \\
\hline
\end{tabular}

Table 2 shows that using the current density programme given in Table 1 the passage of $84 \%$ of the theoretical charge removes at least $70 \%$ of the total salt content in the diluate stream (mother liquor) but with a loss of $24 \%$ of the initial amino acid. Due to the high 
price of the amino acid this amount was considered too high and a new study was started in order to decrease this loss.

Table 2

Mass balance carried out using the results shown in the Table I

\begin{tabular}{llllll}
\hline Species & $\begin{array}{l}\text { Initial diluate } \\
(\mathrm{mol})\end{array}$ & $\begin{array}{l}\text { Final diluate } \\
(\mathrm{mol})\end{array}$ & $\begin{array}{l}\text { Initial concentrate } \\
(\mathrm{mol})\end{array}$ & $\begin{array}{l}\text { Final concentrate } \\
\text { (mol) }\end{array}$ & $\xi$ \\
\hline $\mathrm{AA}$ & 0.345 & 0.261 & - & 0.090 & +1.7 \\
$\mathrm{PO}_{4}$ & 2.137 & 0.641 & 0.074 & 1.667 & +4.4 \\
$\mathrm{SO}_{4}$ & 4.146 & 0.914 & 0.074 & 3.347 & +1.0 \\
\hline
\end{tabular}

\subsection{The influence of the concentration of $D$ - $\alpha$-p-hydroxiphenylglycine.}

Several experiences were carried out diluting the mother liquor in different ratios. The composition of the concentrate and the electrodic chamber solution were the same as before. The current density programme used was the same that given in Table 1. Table 3 shows the results obtained. The initial volume of the diluate stream was maintained constant by addition of water $\left(\mathrm{V}_{\mathrm{H} 2 \mathrm{O}}\right)$. It is clearly seen that the loss of amino acid decreases with dilution while the removing of sulphate slightly increases and the removing of phosphate slightly decreases. Because a loss lower than $15 \%$ was considered acceptable to be incorporated to the main process dilution of $1 / 2$ was considered as optimum. Greater dilution produce an unacceptable increases in the energetic cost needed for concentrate the final diluate stream in order to adequate its concentration to the convenient one for the crystallisation step.

\begin{tabular}{|c|c|c|c|c|c|}
\hline DIL & $\begin{array}{l}c_{\text {Aa }} \\
(\mathrm{mol} / \mathrm{l})\end{array}$ & $\begin{array}{l}V_{\mathrm{H}>\mathrm{O}} \\
\text { (1) }\end{array}$ & $\begin{array}{l}L_{\mathrm{AA}} \\
(\%)\end{array}$ & $\begin{array}{l}R_{50} \\
(\tau)\end{array}$ & $\begin{array}{l}R_{\mathrm{PL}} \\
(\%)\end{array}$ \\
\hline$[/]$ & 0.111 & 1.6 & 20 & 79 & 70 \\
\hline $2 / 3$ & 0.074 & 1.1 & 18 & 81 & 69 \\
\hline $1.5 / 3$ & 0.055 & 0.85 & 13 & 83 & 67 \\
\hline
\end{tabular}

\subsection{Influence of the percentage of charge passed.}

In order to study the influence of the charge passed on the removal of the salts an experience was carried out in which this removal was measured related to the charge passed. The initial concentrations and the conditions of the experience are given in Table 4. Fig. 3 shows the amino acid loss as well as the removal of the salt versus the percentage of charge circulated. When the charge passed is between $85 \%-90 \%$ of the theoretical charge, the loss of the amino acid is $14 \%$ being the removal of the sulphates and phosphates grater than $70 \%$. 


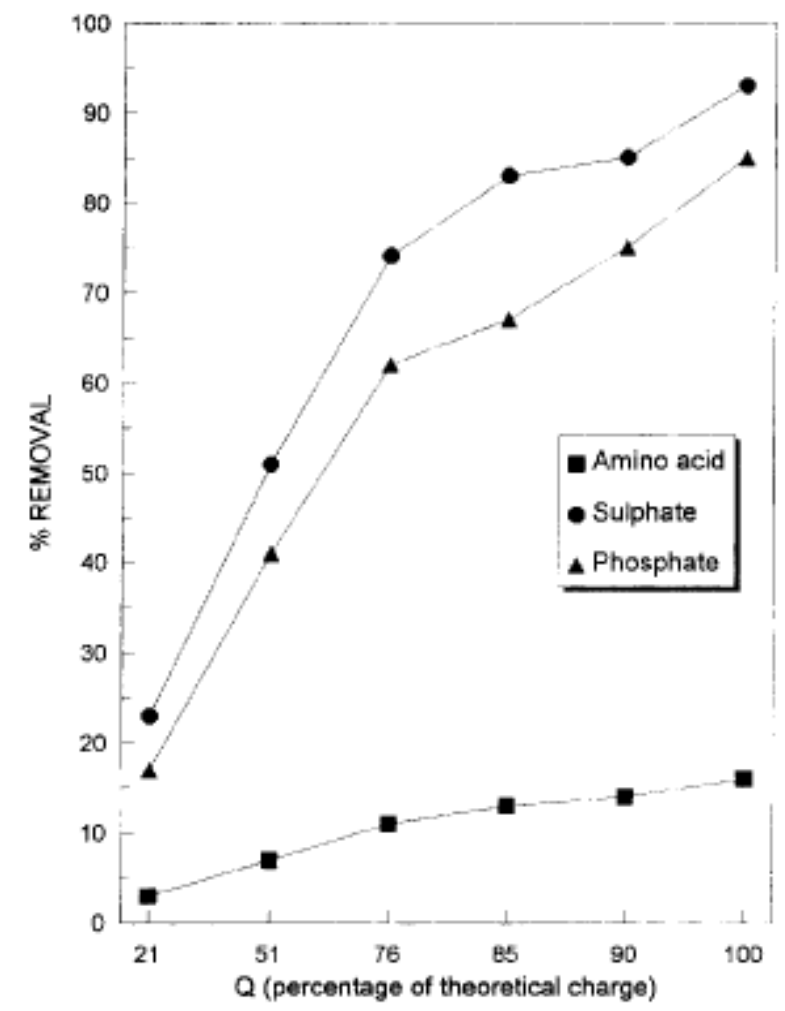

Fjg. 5. Results of the experiment cirried out in order to study the influence of the percentage of charge circulated.

Table 4

The initial concentrations and the conditions for the experiment carried out in order to study the influence of the percentage of charge passed during electrodialysis

\begin{tabular}{|c|c|c|c|c|c|c|c|c|}
\hline \multicolumn{5}{|c|}{ Diluate } & \multicolumn{4}{|c|}{ Concentrate } \\
\hline $\mathrm{pH}$ & $\begin{array}{l}\kappa \\
\left(\Omega^{-1} \mathrm{~m}^{-1}\right)\end{array}$ & $\begin{array}{l}\mathrm{so}_{4} \\
(\mathrm{~mol} / \mathrm{l})\end{array}$ & $\begin{array}{l}\mathrm{Cro}_{4} \\
(\mathrm{~mol} / \mathrm{l})\end{array}$ & $\begin{array}{l}c_{\mathrm{AA}} \\
(\mathrm{mol} / / \mathrm{l}\end{array}$ & $\mathrm{pH}$ & $\begin{array}{l}\left(\mathrm{sel}_{3}\right. \\
\text { (mol/h) }\end{array}$ & $\begin{array}{l}\left(\mathrm{pr}_{4}\right. \\
(\mathrm{nol} / \mathrm{l})\end{array}$ & $\begin{array}{l}c_{\mathrm{AA}} \\
(\mathrm{mol} / /)\end{array}$ \\
\hline$\overline{3.8}$ & 9.0 & 0,643 & 0.371 & 0.055 & 4.1 & 0.045 & 0.045 & - \\
\hline
\end{tabular}

Linear velocity of diluate and concentrate $=0.076 \mathrm{~m} \mathrm{~s}$ ?

\subsection{Long term study.}

Electrodialysis runs were carried out in order to study the influence of time on the behaviour of the electrodialysis, percentage of removal, amino acid loss, stability of the electrodes and membranes etc.. The initial conditions are shown in Table 5 and Table 6 shows the programme of the current density employed for the different percentages of charge passed. The result obtained after the 38 runs ( 319 hours of electrodialysis ) were: average loss of the amino acid of $13 \%$ of the initial content and a removal of the salt of $78 \%$ of the initial sulphate and $84 \%$ of the initial phosphates. 


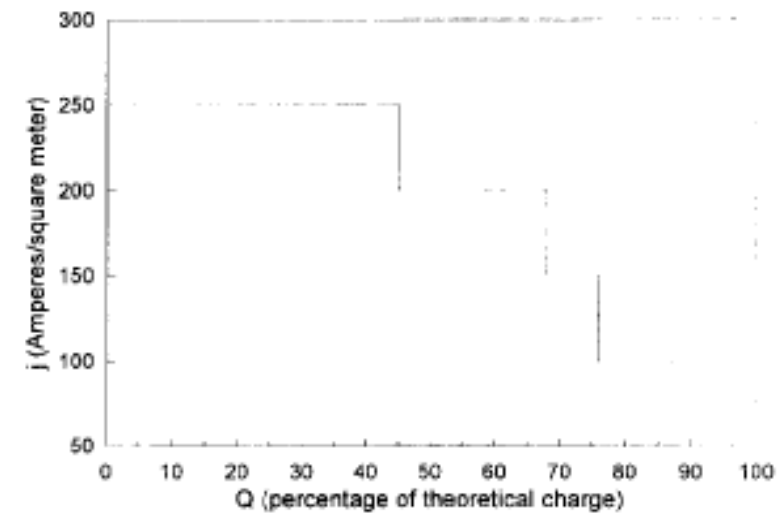

Fig. 6. Current density programme employed in the long term study.

Table 5

Initial concentrations and conditions for the runs carried out in order to study the influence of time on the different electrodialytic parameters

\begin{tabular}{|c|c|c|c|c|c|c|c|c|}
\hline \multicolumn{5}{|c|}{ Diluate } & \multicolumn{4}{|c|}{ Concentrate } \\
\hline $\mathrm{pH}$ & $\stackrel{\kappa}{\left(\Omega^{1} \mathrm{~m}^{-1}\right)}$ & $\begin{array}{l}c_{\mathrm{so}} \\
(\mathrm{mol} / \mathrm{l})\end{array}$ & $\begin{array}{l}{ }_{\mathrm{POO}_{4}} \\
(\mathrm{~mol} / \mathrm{l})\end{array}$ & $\begin{array}{l}c_{\mathrm{AA}} \\
(\mathrm{mol} / /)\end{array}$ & $\mathrm{pH}$ & $\begin{array}{l}r \\
\left(\Omega \Omega^{-1} \mathrm{~m}^{-1}\right)\end{array}$ & $\begin{array}{l}4 \mathrm{SO}_{4} \\
\langle\mathrm{~mol} / \mathrm{s}\end{array}$ & $\begin{array}{l}c_{\mathrm{PO}_{4}} \\
(\mathrm{~mol} / 1)\end{array}$ \\
\hline 3.8 & 8.7 & 0.667 & 0.344 & 0.056 & 4.5 & 1.5 & 0.050 & 0.050 \\
\hline
\end{tabular}

Linear velocity of diluate and concentrate stream $=0.076 \mathrm{~m} \mathrm{~s}^{-1}$.

Charge passed $=90 \%$ of the theoretical $\left(Q_{1}\right)$

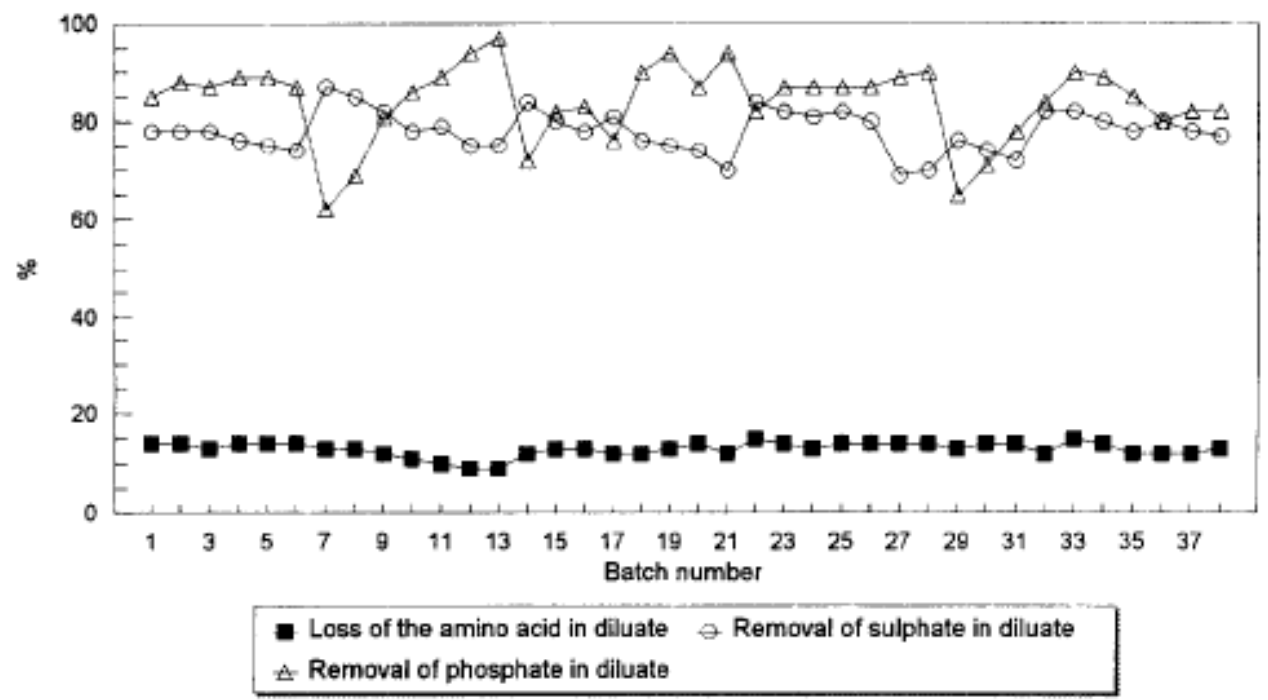

Fig. 7. Long term study, Loss of amino acid and salt removal versus batch number

\section{Conclusions.}

It is possible by using electrodialysis to remove a high percentage of salt (more than $70 \%$ ) from a $\mathrm{D}$ - $\alpha$-p-hydroxyphenylglycine solution with a amino acid loss between 12 $14 \%$ of the initial content. This process allow the diluate to be reintroduced in the main process after a concentration step if needed.

This process has been patented (10).

\section{5.. List of symbols}




\begin{tabular}{ll}
$\mathrm{PO}_{4}$ & concentration of phosphate, mol.m \\
$\mathrm{SO}_{4}$ & concentration of sulphate, mol.m \\
$\mathrm{DIL}$ & dilution ratio of the mother liquor \\
$\mathrm{gAA}(\mathrm{FD})$ & grams of amino acid in final diluate \\
$\mathrm{gAA}(\mathrm{ID})$ & \multicolumn{1}{c}{ grams of amino acid in initial diluate } \\
$\mathrm{gPO}_{4}(\mathrm{FD})$ & grams of phosphate in final diluate \\
$\mathrm{gPO}_{4}(\mathrm{ID})$ & grams of phosphate in initial diluate \\
$\mathrm{gSO}_{4}(\mathrm{FD})$ & grams of sulphate in final diluate \\
$\mathrm{gSO}_{4}(\mathrm{ID})$ & Grams of sulphate in initial diluate \\
$\mathrm{j}$ & current density, A.m \\
$\mathrm{Q}$ & percentage of the theoretical charge required \\
$\mathrm{Q}_{\mathrm{T}}$ & theoretical charge required to remove all salt \\
$\mathrm{V}$ & voltage, V. \\
$\mathrm{V}_{\mathrm{H} 20}$ & volume of water, L. \\
$\% \mathrm{LAA}^{-2}$ & percentage of loss of the amino acid \\
$\% \mathrm{RPO}_{4}$ & percentage of removal of phosphate \\
$\% \mathrm{RSO}_{4}$ & percentage of removal of sulphate \\
$\kappa$ & conductivity, $\Omega^{-1} \mathrm{~m}^{-1}$
\end{tabular}

\section{References}

\#\#\#1\#\#\# T-Matsui, Electrodialysis type anion exchange apparatus, and operating method thereof., Japan kokai Tokkyo Koho, JP94134266 A2 (05/17/94).

\#\#\#2\#\#\# Dong-Hwang Chen, Sung-Shyong Wang, Ting-Chia Huang. Separation of phenylacetic acid, 6 aminopenicillanic acid and penicillin $\mathrm{G}$ with electrodialysis under constant current, J.Chem Technol.Biotechnol. 64(3) (1995) 284.

\#\#\#3\#\# Ken-ichi Kikuchi, Takeshi Gotoh, Hiroshi Takashashi, Shuichi Higashino, Joshua S. Dranoff, Separation of amino acids by electrodialysis with ion-exchange membranes, J.Chem. Eng. Jpn. 28(1) (1995) 103.

\#\#\#\#\#\# Jean Pierre Le Goff, Claude Gavach, Roger Sandeuax, Jacqueline Sandeaux, Separation of amino acid mixture, PCT International, WO 9207818 A1 (14/05/92)

\#\#\#\#\#\# V. Golubev, Salem Benamara, Membrane techniques in the purification and separation of amino acids, Ind. Aliment. Agric, 108(12) (1991) 1075.

\#\#\#6\#\# Frederick Chlanda, PCT International, WO 9102584 A1 (14/08/89).

\#\#\#\#\#\# Tetsuo Nakamura, Yukitaka Syukunobe, Akira Tomizawa, Akinori Shigematsu, Masanobu Koutake, Nippon Shokukhin Kogyo Gakkaishi 40 (1993) 545

\#\#\#8\#\# Tdashi Mizuno, Fumihiko Nichiki, Nobuaki Tabei, Haruki Okamura, Motomasa Oosu, Japn Kokai Tokkyo Koho, JP 9166663 A2 (22/03/91).

\#\#\#9\#\# Kazuhisa Sato, Tetsuya Sakairi, Toshikuni Yonemoto, Teiriki Tadaki, J.Membr. Sci. 100(3) (1995) 209.

\#\#\#10\#\#\# A. Aldaz, V. Montiel, V. G. García. Procedimiento para la recuperación de D-(-)- $\alpha-p-$ hidroxifenilgilicina mediante electrodiálisis. P9501966. (10-11-959. 